\title{
INTESTINAL ABSORPTION OF BILE PIGMENTS. I. THE ENTEROHEPATIC CIRCULATION OF BILIRUBIN IN THE RAT *
}

\author{
By ROGER LESTER AND RUDI SCHMID \\ (From the Thorndike Memorial Laboratory and the Second and Fourth [Harvard] Medical \\ Services, Boston City Hospital, and the Department of Medicine, Harvard Medical
}

School, Boston, Mass.)

(Submitted for publication December 31, 1962; accepted January 30, 1963 )

Despite much investigative work, the existence and magnitude of intestinal absorption of bilirubin have not been established (1-5). Earlier studies of this problem have been limited by methodologic inadequacies involving identification, isolation, and estimation of bilirubin and its derivatives. Moreover, newer concepts of the physiology of absorption (6-9) have invalidated certain of the assumptions inherent in previous studies. For example, demonstrated differences in the absorption of polar and nonpolar organic compounds (10-12) suggest that conjugated bilirubin as it exists in bile $(13,14)$ may be handled differently by the intestinal mucosa from the unconjugated pigment employed in many of the earlier investigations (2, $4,15)$. In addition, recent observations have indicated that, in the intestinal wall, absorption may be coupled with chemical modification; specifically, it has been shown that absorbed substances may be converted to their glucuronides (16-18). This might suggest that bilirubin is conjugated by the intestinal mucosa rather than absorbed unaltered.

The preparation of radiochemically pure bilirubin- $\mathrm{C}^{14}$ (19) has facilitated experimental study of this problem. In the present investigation, free (unconjugated) or conjugated bilirubin- $\mathrm{C}^{14}$ was instilled into the intestinal tract of rats prepared with an external bile fistula. Samples of bile, urine, and feces from these animals were assayed for radioactivity, and the amount of labeled bilirubin excreted in bile was determined. The data obtained permitted estimation of the magnitude of intestinal absorption of these two pigments (20, 21).

Preliminary reports of similar observations in man have been published from this laboratory (21)

\footnotetext{
* Supported in part by U. S. Public Health Service grant A-1833.
}

and by Gilbertsen, Bossenmaier, and Cardinal (22).

\section{MATERIALS AND METHODS}

In the following studies the term "absorption" is used to describe unidirectional absorptive flux of bilirubin, rather than net intestinal absorption (flux from gut to blood minus flux from blood to gut). In interpreting the data it should be noted that transfer of unconjugated bilirubin from the body pool to the gut lumen has been demonstrated in rats with congenital hyperbilirubinemia (23).

Preparation of radioactive pigments. Crystalline unconjugated bilirubin- $\mathrm{C}^{14}$ with specific activities ranging from 300 to $2,000 \mathrm{dpm}$ per $\mu \mathrm{g}$ (disintegrations per minute per microgram) was prepared by biosynthetic techniques described previously (19). In preliminary studies of intestinal absorption, unconjugated bilirubin- $\mathrm{C}^{\mathbf{1 4}}$ was administered into the duodenum dissolved in rat bile, in $5 \%$ human albumin solution, or in aqueous solutions of chromatographically pure ${ }^{1}$ (24), or commercially available taurocholate. Since in all instances the patterns of absorption were similar, in subsequent experiments unconjugated bilirubin- $\mathrm{C}^{\mathbf{1 4}}$ was administered dissolved in 5 to $10 \mathrm{mM}$ commercial taurocholate.

In order to prepare conjugated bilirubin- $\mathrm{C}^{14}$, unconjugated bilirubin- $\mathrm{C}^{14}$ was infused intravenously into Sprague-Dawley rats with an external biliary fistula. During the ensuing 3 hours, virtually all injected labeled pigment was excreted in the bile as conjugated bilirubin$\mathrm{C}^{14}$ (25). Bile specimens were collected in the dark at $4^{\circ} \mathrm{C}$ and stored at $-30^{\circ} \mathrm{C}$ for brief intervals before use. In studies of absorption, conjugated bilirubin- $\mathrm{C}^{41}$ was administered in native bile without further purification.

Preparation of experimental animals and administration of radioactive pigment. Fasting male SpragueDawley rats weighing 300 to $450 \mathrm{~g}$ were anesthetized by intraperitoneal administration of $2 \mathrm{mg}$ per $100 \mathrm{~g}$ pentobarbital, and anesthesia was then maintained by intermittent inhalation of ethyl ether. An $8-\times 8-\mathrm{cm}$ cellophane square was sutured around the anus, permitting separate collection of urine and feces. Laparatomy was performed

1 The authors are indebted to Dr. Kurt J. Isselbacher for supplying the chromatographically pure taurocholate utilized in these experiments. 


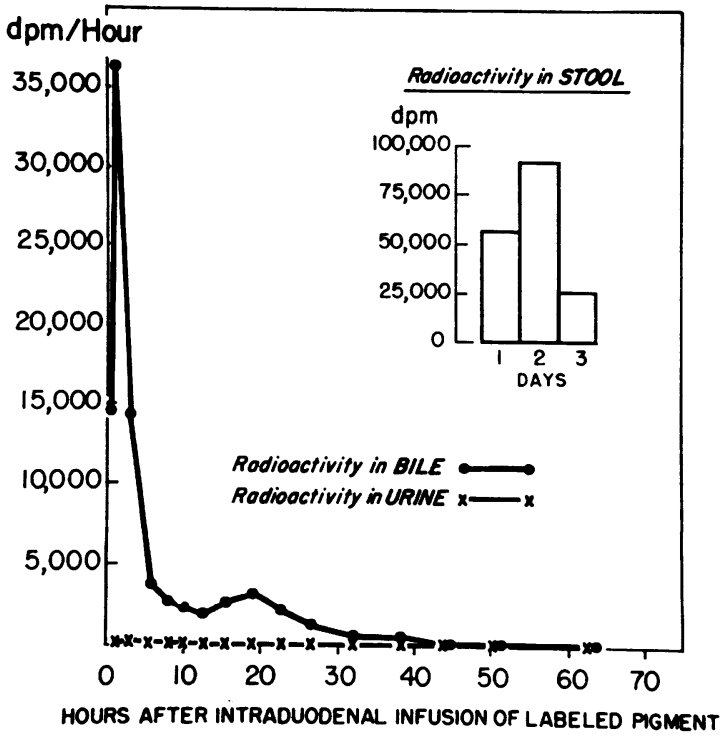

Fig. 1. RADIOACTIVITY IN EXCRETA AFTER ADMINISTRATION OF UNCONJUGATED BILIRUBIN-C ${ }^{14}$ INTO THE DUODExis of a Sprague-Dawley rat with an external bile FISTCLA. $d p m=$ disintegrations per minute.

and the bile duct obstructed distally with a ligature. A PE-10 polyethylene catheter ${ }^{2}$ was inserted into the proximal portion of the duct, secured in place, and brought through a stab wound in the skin for external drainage. After bile flow was established, under direct observation a PE-50 polyethylene tube 2 was passed transorally into the second portion of the duodenum, through which 1.5 to $3 \mathrm{ml}$ of the solution containing labeled pigment was infused (Figure 1). After removal of the duodenal tube and closure of the laparotomy wound, the rats were placed in restraining cages and allowed to recover from the anesthesia.

Bile was drained into tubes kept at $4^{\circ} \mathrm{C}$ in the dark and changed at frequent intervals. All bile, urine, and stool specimens were collected separately and quantitatively, and stored at $-30^{\circ} \mathrm{C}$ until analyzed. Hydration and alimentation were maintained orally by offering drinking solution $(0.2 \% \mathrm{NaCl}, 0.02 \% \mathrm{KCl}$, and $2.5 \%$ glucose) and pellets of rat chow. If required, additional fluid was administered subcutaneously in the form of isotonic saline or $5 \%$ glucose and water. Approximately 24 to 72 hours after pigment administration, the animals were killed and autopsied for inspection of the operative site. Segments of intestine exposed to the highest concentrations of bilirubin and taurocholate employed in these experiments were sectioned and stained with eosin and hematoxylin for histologic examination.

Similar experiments, with and without bile duct catheterization, were performed in Gunn rats exhibiting hereditary nonhemolytic hyperbilirubinemia $(26,27)$. Six to 24 hours after pigment administration, each animal was

\footnotetext{
2 Clay-Adams, Inc.. New York, N. Y.
}

exsanguinated, and serum samples were stored in the dark at $-30^{\circ} \mathrm{C}$ until analyzed.

Absorption of labeled pigment was also studied in individual intestinal segments with intact blood supply. In Sprague-Dawley rats prepared with an external biliary fistula, 5- to $15-\mathrm{cm}$ loops of small or large bowel were isolated in situ, flushed with isotonic saline, and closed at one end with a ligature. A 1 - to $3-\mathrm{ml}$ solution containing the radioactive pigment was introduced through the other end, which was then ligated. After closing the laparotomy wound, bile was collected over a 5-hour period as described above.

In three fasted Sprague-Dawley rats the terminal ileum was obstructed with a single ligature, and unconjugated bilirubin- $\mathrm{C}^{14}$ was administered through a transoral tube into the duodenum. The experiment was terminated 1 hour later by slow aspiration of blood from the portal vein, and the serum obtained was stored in the dark at $-30^{\circ} \mathrm{C}$.

Biochemical detcrminations and radioassay. Bilirubin concentrations in the bile were determined by the diazo reaction (28). For radioassay in a Packard Tri-Carb liquid scintillation spectrometer, $0.05-\mathrm{ml}$ samples of bile were pipetted into low-potassium glass counting vials, ${ }^{3}$ and then dissolved in $1 \mathrm{ml}$ of $1 \mathrm{M}$ Hyamine ${ }^{4}$ in methanol, and $17 \mathrm{ml}$ of scintillator solution. ${ }^{5}$ Bilirubin from each bile sample was then crystallized and recrystallized, and its specific activity was measured by methods previously described (19). To bile from Gunn rats, which contains only traces of bilirubin $(23,27)$, freshly collected normal (Sprague-Dawley) rat bile was added to provide sufficient conjugated bilirubin to serve as carrier for crystallization. Comparison of data obtained from whole bile and from bilirubin crystallized therefrom permitted estimation of total excreted radioactivity and of the proportion of radioactivity excreted as conjugated bilirubin- $\mathrm{C}^{\mathbf{1 4}}$.

Radioactivity in urine was determined by dissolving $0.05-\mathrm{ml}$ samples in $1 \mathrm{ml}$ of $1 \mathrm{M}$ Hyamine and $17 \mathrm{ml}$ of scintillator solution for radioassay in a Packard TriCarb liquid scintillation spectrometer. In addition, 1-ml portions of urine were dried in low-potassium glass counting vials at $70^{\circ} \mathrm{C}$ and the residue dissolved in $1 \mathrm{ml}$ of $1 \mathrm{M}$ Hyamine before adding the scintillator fluid. Stool samples were boiled for 2 hours in several volumes of $1 \mathrm{~N} \mathrm{NaOH}$. After cooling and adding an equal volume of ethanol, the dark mixture was homogenized and filtered through Whatman no. 1 filter paper. Radioactivity was determined on $0.05-\mathrm{ml}$ samples of the clear filtrate as described above for bile. Interference in scintillation counting introduced by fluorescing compounds in

${ }^{3}$ Catalog no. 6001015, Packard Instrument Co., La Grange, I11.

${ }^{4}$ Hydroxide of Hyamine $10 \times$, Packard Instrument Co., La Grange, I11.

${ }^{5}$ Liquifluor, concentrated liquid scintillator, diluted 25 times with toluene, Pilot Chemicals, Inc., Watertown, Mass. 
TABLE I

Intestinal absorption of bilirubin-C ${ }^{14}$ in male Sprague-Dawley rats

\begin{tabular}{|c|c|c|c|c|c|c|c|c|c|}
\hline \multirow[b]{3}{*}{ Rat } & \multirow[b]{3}{*}{ Weight } & \multirow{3}{*}{$\begin{array}{c}\text { Pigment } \\
\text { administered }\end{array}$} & \multicolumn{3}{|c|}{$\begin{array}{c}\text { Characteristics of ad- } \\
\text { ministered material }\end{array}$} & \multirow{3}{*}{$\begin{array}{l}\text { Duration } \\
\text { of experi- } \\
\text { ment }\end{array}$} & \multirow{2}{*}{\multicolumn{3}{|c|}{ Recovered radioactivity $\dagger$}} \\
\hline & & & \multirow{2}{*}{\multicolumn{2}{|c|}{ Volume $\begin{array}{c}\text { Bilirubin } \\
\text { concen- } \\
\text { tration }\end{array}$}} & \multirow[b]{2}{*}{ Radioactivity } & & & & \\
\hline & & & & & & & Bile & Urine & Feces \\
\hline $\begin{array}{c}n o . \\
1\end{array}$ & $\begin{array}{c}g \\
290\end{array}$ & $\begin{array}{l}\text { Unconjugated } \\
\text { bilirubin-C }{ }^{14}\end{array}$ & $\begin{array}{c}m l \\
2.0\end{array}$ & $\begin{array}{c}m g / 100 m l \\
59.9\end{array}$ & $\begin{array}{c}d p m^{*} \\
545,000\end{array}$ & $\begin{array}{l}\text { hrs } \\
72\end{array}$ & $\begin{array}{l}\% \\
28\end{array}$ & $\begin{array}{l}\% \\
<1\end{array}$ & $\begin{array}{l}\% \\
32\end{array}$ \\
\hline 2 & 460 & $\begin{array}{l}\text { Unconjugated } \\
\text { bilirubin-C }\end{array}$ & 1.9 & 12.5 & 139,000 & 72 & 8 & $<1$ & 9 \\
\hline 3 & 385 & $\begin{array}{l}\text { Unconjugated } \\
\text { bilirubin-C }{ }^{14}\end{array}$ & 1.8 & 20.4 & 416,000 & 23 & 25 & 1 & 43 \\
\hline $4 \ddagger$ & 410 & $\begin{array}{l}\text { Unconjugated } \\
\text { bilirubin-C }\end{array}$ & 1.8 & 17.7 & 272,000 & 72 & 22 & trace & 40 \\
\hline $5 \ddagger$ & 420 & $\begin{array}{l}\text { Unconjugated } \\
\text { bilirubin-C }{ }^{14}\end{array}$ & 1.8 & 12.0 & 428,000 & 8 & 16 & $<1$ & $\begin{array}{c}\text { not } \\
\text { measured }\end{array}$ \\
\hline 6 & 360 & $\begin{array}{l}\text { Conjugated } \\
\text { bilirubin-C }\end{array}$ & 1.8 & 33.0 & 290,000 & 75 & 21 & 2 & 40 \\
\hline 7 & 380 & $\begin{array}{l}\text { Conjugated } \\
\text { bilirubin-C }\end{array}$ & 2.1 & 28.8 & 283,000 & 72 & 40 & 2 & 39 \\
\hline 8 & 490 & $\begin{array}{l}\text { Conjugated } \\
\text { bilirubin-C }\end{array}$ & 3.0 & 25.3 & 408,000 & 72 & 14 & $<1$ & 52 \\
\hline $9 \ddagger$ & 485 & $\begin{array}{l}\text { Conjugated } \\
\text { bilirubin-C }{ }^{14}\end{array}$ & 2.3 & 15.7 & 249,000 & 75 & 22 & $<1$ & 76 \\
\hline $10 \ddagger$ & 420 & $\begin{array}{l}\text { Conjugated } \\
\text { bilirubin-C }\end{array}$ & 1.9 & 23.5 & 228,000 & 70 & 4 & $<1$ & 39 \\
\hline
\end{tabular}

* Disintegrations per minute.

$\dagger$ Percentage of administered dose.

$\ddagger$ Pretreated for 10 days with oral neomycin, 0.05 to $0.1 \mathrm{mg}$ per g body weight per day.

stool and urine samples was quenched by adjusting the final counting solution to $\mathrm{pH} 6$ with glacial acetic acid.

The serum obtained from Gunn rats was assayed for bilirubin concentration by the diazo reaction (28), and radioactivity was determined by using $0.05-\mathrm{ml}$ samples as described for bile. Bilirubin was crystallized from the remainder of the serum by Najjar and Childs' method (29) modified as follows. Serum, $3 \mathrm{ml}$ adjusted to $\mathrm{pH}$ 5 with $0.3 \mathrm{M}$ acetate buffer, was extracted repeatedly into 50 - to $200-\mathrm{ml}$ vol of peroxide-free ethyl ether. After washing the combined ether extracts 4 times with distilled water, the bilirubin was transferred into 15 to $25 \mathrm{ml}$ of $0.01 \mathrm{M}$ sodium pyrophosphate. The $\mathrm{pH}$ of the pyrophosphate solution was reduced with glacial acetic acid displacing the bilirubin into chloroform. The latter was washed rapidly 6 times with distilled water, once with $10 \%$ saline, and 4 more times with water. After filtration through chloroform-moistened filter paper, bilirubin was crystallized and recrystallized, and the specific activity of the crystals was determined by methods described previously (19).

Unlabeled carrier bilirubin was added to serum samples obtained from the portal vein of Sprague-Dawley rats that had received intraduodenal unconjugated bilirubin- $\mathrm{C}^{\mathbf{1 4}}$. The pigment was then extracted and crystallized as described above.
For radioassay, all samples (bile, urine, stool extract, and bilirubin crystals) were counted in a Packard TriCarb liquid scintillation spectrometer and radioactivity was expressed in distintegrations per minute with toluene- $\mathrm{C}^{14}$ as an internal standard. ${ }^{6}$ Results from samples with low radioactivity were treated statistically $(30)$ to ascertain the presence of a significant number of counts above background $(\mathrm{p}<.01)$.

Assay of intestinal mucosa for $\beta$-glucuronidase. Three fasting male Sprague-Dawley rats and a male Gunn rat were killed by decapitation, the entire small bowel was removed, and the mucosa stripped from the small bowel with a steel spatula. After the mucosa was weighed, it was homogenized in a chilled Potter-Elvehjem glass homogenizer. $\beta$-Glucuronidase was extracted from the homogenate, and the crude enzyme preparation assayed with phenolphthalein glucuronide as the substrate (31). Enzymatic activity was expressed in units (31) per milligram wet weight of mucosa.

Experiments with everted intestinal sacs. Everted sacs of rat or hamster jejunum and ileum were prepared by the method of Wilson and Wiseman (32). ${ }^{7}$ The incu-

\footnotetext{
${ }^{6}$ New England Nuclear Corp., Boston, Mass.

i The authors are indebted to Dr. T. Hastings Wilson and to Dr. Victor Herbert for instruction in this tech-
} nique. 
bating fluid contained 5 to $15 \mathrm{mg}$ per $100 \mathrm{ml}$ bilirubin dissolved in 1 to $5 \mathrm{~g}$ per $100 \mathrm{ml}$ human albumin or 1 to 6 $\mathrm{mM}$ taurocholate, and $200 \mathrm{mg}$ per $100 \mathrm{ml}$ glucose in Krebs-Ringer bicarbonate solution. The serosal fluid was composed identically, except for the exclusion of bilirubin. In addition, experiments were carried out with albumin solution on the serosal side and bilirubin, dissolved in taurocholate, on the mucosal side. The sacs were incubated with constant shaking for 1 hour at $37^{\circ}$ $\mathrm{C}$ in $95 \%$ oxygen and $5 \%$ carbon dioxide, after which serosal and mucosal fluid was analyzed for bilirubin (28) and glucose (33) concentrations.

\section{RESULTS}

Intestinal absorption of labcled pigment. In 10 Sprague-Dawley rats with an external biliary fistula, absorption of labeled pigment infused into the duodenum was studied for periods ranging from 8 to 75 hours (Table I). With both unconjugated bilirubin- $\mathrm{C}^{14}$ and conjugated bilirubin$\mathrm{C}^{14}$, significant amounts of isotopic material were absorbed, as demonstrated by excretion of 4 to $40 \%$ of the administered labeled pigment in the bile. Over the same period of time, only traces to $2 \%$ of the infused isotope appeared in the urine (Table I). A major fraction of the administered radioactivity remained unabsorbed and was recovered in the excreted feces.

In rats 1 to 5 infused with unconjugated bili-

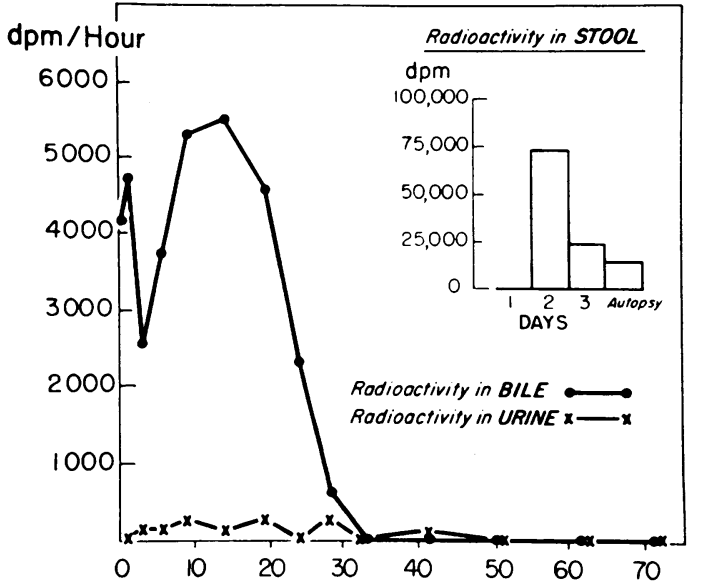

HOURS AFTER INTRADUODENAL INFUSION OF LABELED PIGMENT

Fig. 2. RadioActivity IN EXCRETA AFTER ADMINISTRATION OF CONJUgated BILIRUBiN-C ${ }^{14}$ INTO THE DUODENUM of a Sprague-Dawley rat with an external bile FISTULA.

rubin- $\mathrm{C}^{14}$ in taurocholate solution (Table I), 8 to $28 \%$ of the labeled pigment was absorbed and excreted in the bile. As a rule, biliary excretion of isotopic material began during the first 30 minutes, reached peak values during the first few hours, and declined over the ensuing 15 to 40 hours nearly asymptotically (Figure 1). In two instances in which the experiment was terminated after 23 and

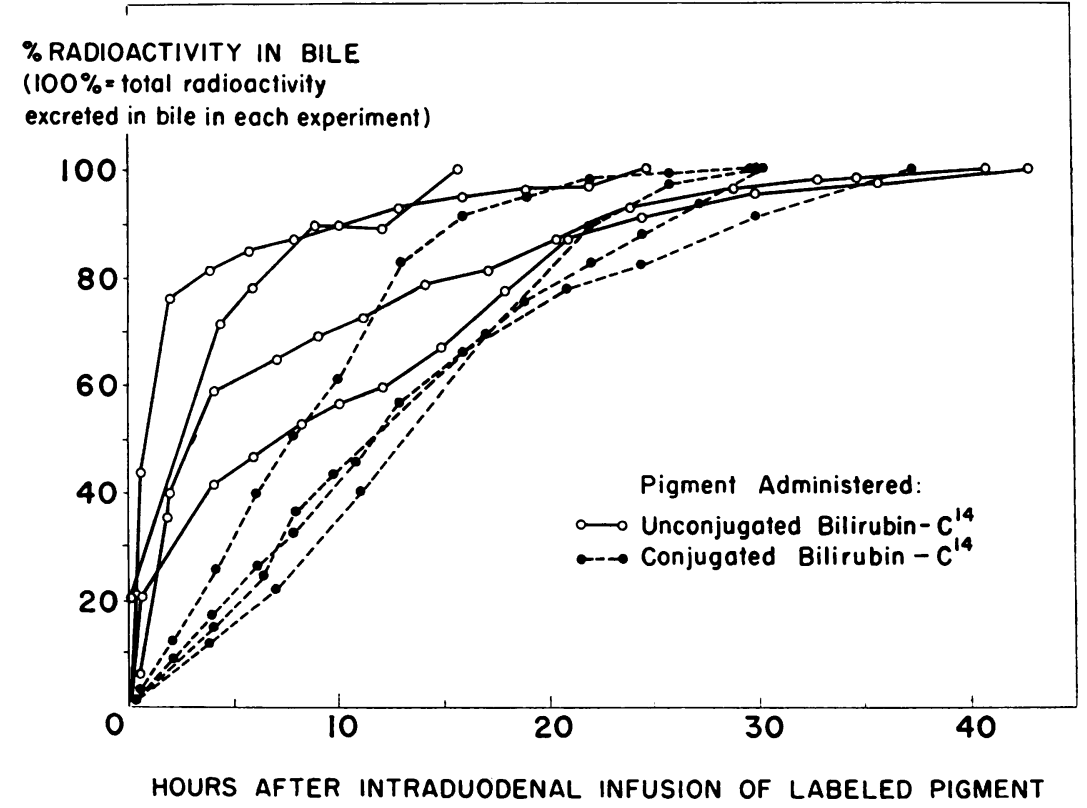

Fig. 3. Cumulative excretion of radioactivity in bile after intraduodenal ADMinistration OF UNCONJUGATEd OR CONJUGATEd BILIRUBin-C ${ }^{14}$. 
TABLE II

Recovery of radioactivity in bilirubin crystallized from bile of rats after intraduodenal administration of labeled pigment

\begin{tabular}{ccc}
\hline & & $\begin{array}{c}\text { Radioactivity recovered } \\
\text { in crystalline bilirubin } \\
\text { expressed as percentage } \\
\text { of total radioactivity } \\
\text { of bile specimen }\end{array}$ \\
Rat & Pigment administered & \\
\hline no. & Unconjugated bilirubin-C & 65 \\
1 & Unconjugated bilirubin-C & 100 \\
2 & Unconjugated bilirubin-C & 53 \\
3 & Unconjugated bilirubin-C & 78 \\
$4^{*}$ & Unconjugated bilirubin-C & 59 \\
$5^{*}$ & Conjugated bilirubin-C & 36 \\
6 & Conjugated bilirubin-C & 48 \\
7 & Conjugated bilirubin-C & 67 \\
8 & Conjugated bilirubin-C & 40 \\
$9^{*}$ & Conjugated bilirubin-C & not measured \\
$10^{*}$ & Conjulit & \\
\hline
\end{tabular}

* Pretreated with neomycin; see Table I.

8 hours, respectively, cumulative excretion of labeled pigment in the bile was similar to that in rats whose collection of excreta was continued for a longer period of time (Table I).

When conjugated bilirubin- $\mathrm{C}^{14}$ was infused into the duodenum (Table I; rats 6 to 10), 4 to $40 \%$ of the administered labeled pigment was absorbed and excreted in the bile. Although radioactivity was demonstrable within 30 minutes, in most instances the early phase of biliary excretion of the isotope was distinctly slower than with unconjugated pigment, and excretion continued for up to 24 hours with relatively little change in rate (Figure 2). This difference in excretory pattern depending on the type of pigment that was administered into the intestinal lumen is illustrated in Figure 3.

In four rats, (Table I; rats 4, 5, 9, and 10) oral neomycin $(0.05$ to $0.1 \mathrm{mg}$ per $\mathrm{g}$ body weight per day) was administered for 10 days before the intraduodenal infusion of radioactive pigment. As seen in Table I, the amount of labeled pigment absorbed and excreted in the bile was similar to that in untreated animals.

Identification of the absorbed labeled pigment. In the above experiments, it was essential to ascertain that a significant fraction of the isotope absorbed from the intestine was re-excreted in the bile in the form of conjugated bilirubin. For this purpose the pigment was crystallized from representative bile samples, and based on its specific activity, the proportion of total biliary radioactivity contained in conjugated bilirubin was calculated for each specimen. As seen in Table II, from 36 to $100 \%$ of the biliary radioactivity could be accounted for as conjugated bilirubin. The proportion of isotope in bilirubin seemed to be slightly higher when unconjugated pigment was infused into the intestine, but the limited number of experiments did not permit adequate statistical evaluation of this apparent difference.

In three rats, portal venous blood was obtained 1 hour after intraduodenal administration of unconjugated bilirubin- $\mathrm{C}^{14}$ in taurocholate solution. After adding unlabeled carrier bilirubin to the serum, the unconjugated pigment was extracted and crystallized. A significant fraction of the radioactivity contained in the portal serum was present in the bilirubin crystals, indicating that during absorption, at least a part of the administered, unconjugated pigment did not undergo chemical alteration.

Additional studies of this problem were carried out in six Gunn rats, four of which were prepared with an external biliary fistula. These icteric animals are unable to conjugate and, hence, to excrete bilirubin, but can readily excrete conjugated pigment that has been introduced into the circulation (27). Consequently, if conjugated bilirubin were absorbed without prior hydrolysis, or if pigment were conjugated in the course of absorption, it would rapidly be excreted in the bile. Contrariwise, all bilirubin that reached the portal blood in unconjugated form would be incorporated into the pigment pool of the body and could be identified in the serum. Since, from experiments reported elsewhere (23), the total pigment pool of Gunn rats was found to be 5 to 7 times larger than the plasma volume, the amount of unconjugated bilirubin- $\mathrm{C}^{14}$ that was absorbed intact from the intestinal tract could be calculated from the specific activity of the serum bilirubin.

As seen in Table III, irrespective of whether unconjugated or conjugated bilirubin- $\mathrm{C}^{14}$ was infused into the intestine, significant levels of radioactivity were found in the serum while the bile contained no more than $6 \%$ of the label. In each instance, crystallization of serum bilirubin and determination of its specific activity revealed that more than two-thirds of the isotope in the serum was present in the form of unconjugated pigment. In contrast, it was estimated that of the small 
TABLE III

Intestinal absorption of bilirubin-C ${ }^{14}$ in Gunn rats

\begin{tabular}{|c|c|c|c|c|c|c|}
\hline $\begin{array}{l}\text { Rat: } \\
\text { Weight, } g:\end{array}$ & $\begin{array}{r}11 \\
185\end{array}$ & $\begin{array}{r}12 \\
250\end{array}$ & $\begin{array}{r}13 \\
160\end{array}$ & $\begin{array}{r}14 \\
350\end{array}$ & $\begin{array}{r}15 \\
240\end{array}$ & $\begin{array}{r}16 \\
250\end{array}$ \\
\hline \multicolumn{7}{|l|}{ Characteristics of administered material } \\
\hline $\begin{array}{l}\text { Pigment } \\
\text { Bilirubin concentration, } m g / 100 \mathrm{ml} \\
\text { Volume, } m l \\
\text { Radioactivity, } d p m^{*}\end{array}$ & $\begin{array}{l}\text { Unconju } \\
37.4 \\
2.2 \\
832,000\end{array}$ & $\begin{array}{l}\text { Igated bilir } \\
21.2 \\
2.6 \\
447,000\end{array}$ & $\begin{array}{r}\text { ubin-C } \\
59.3 \\
2.4 \\
579,200\end{array}$ & $\begin{array}{r}\text { Conjug } \\
54.2 \\
2.6 \\
1,123,000\end{array}$ & $\begin{array}{c}\text { ated bilirub } \\
27.4 \\
4.4 \\
742,000\end{array}$ & $\begin{array}{r}27.8 \\
3.5 \\
482,000\end{array}$ \\
\hline Duration of experiment, $h r s$ & 24 & 18 & 6 & 24 & 24 & 24 \\
\hline $\begin{array}{l}\text { Estimated radioactivity absorbed and retained } \\
\text { in body pool, percentage of administered } \\
\text { doset }\end{array}$ & 14 & 34 & 8 & 19 & 19 & 17 \\
\hline $\begin{array}{l}\text { Estimated unconjugated bilirubin- } \mathrm{C}^{14} \text { absorbed } \\
\text { and retained intact in body pool, percentage } \\
\text { of administered dose } \ddagger\end{array}$ & 10 & 34 & 6 & 16 & 15 & 12 \\
\hline $\begin{array}{l}\text { Percentage of administered radioactivity ex- } \\
\text { creted in bile }\end{array}$ & & 4 & 0.8 & 0.9 & & 6 \\
\hline $\begin{array}{l}\text { Percentage of administered radioactivity present } \\
\text { in bile as conjugated bilirubin- } C^{14}\end{array}$ & & $<1$ & $<0.2$ & $<0.2$ & & $<1$ \\
\hline
\end{tabular}

* Disintegrations per minute.

$\dagger$ Body pool dpm (23)/dose dpm $\times 100$.

$\ddagger$ Bilirubin-C $C^{14}$ body pool (23)/bilirubin-C ${ }^{14}$ dose $\times 100$.

amount of radioactivity in the bile, less than onequarter was excreted in the form of labeled conjugated bilirubin.

Absorption of pigment from isolated intestinal scgments. With rat and hamster everted gut sacs (32). transfer of unconjugated bilirubin into the serosal fluid could not be demonstrated in vitro despite the manipulation of experimental conditions described above (see Materials and Methods) and the presence of active transport (34) of glucose. Gross adsorption of bilirubin on the mucosal surface was noted.

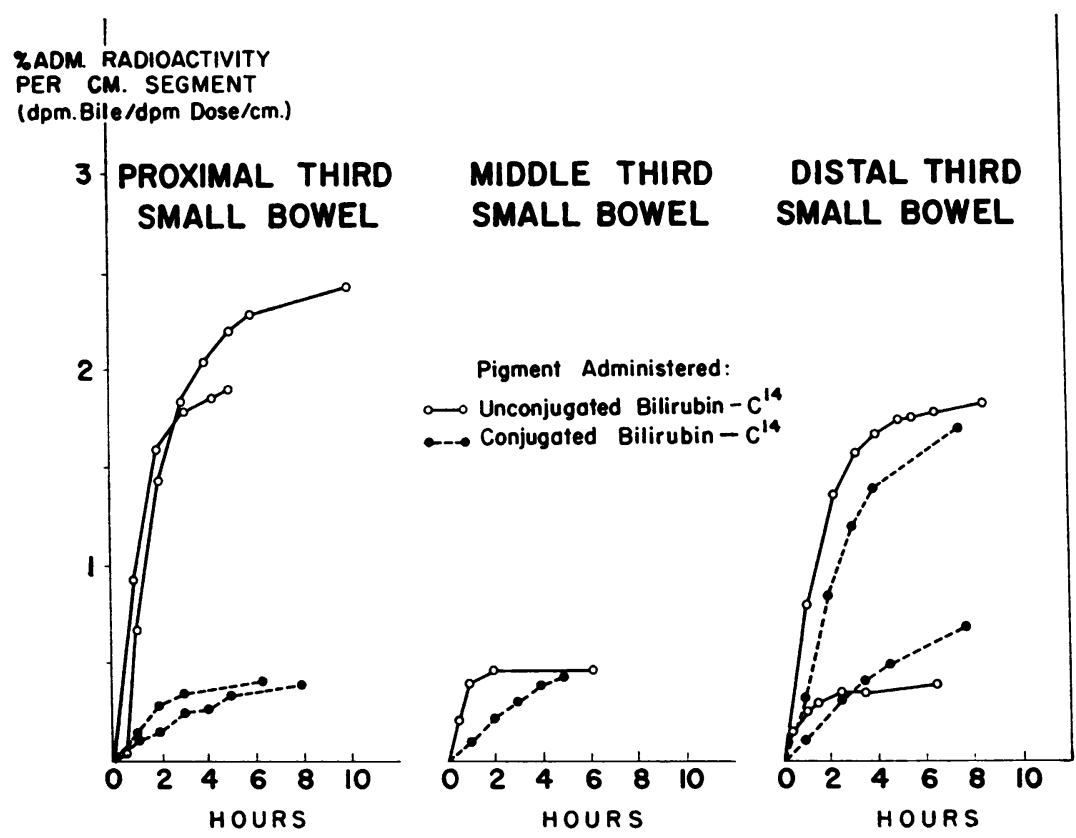

Fig. 4. Radioactivity in Bile After administration of Bilirubin-C ${ }^{14}$ into ISOLATED SEGMENTS OF SMALL BOWEL. 
Consequently, the locus of pigment adsorption was investigated in vivo by isolating individual intestinal segments in rats prepared with an external biliary fistula. As seen in Figure 4, with conjugated and unconjugated pigment, labeled pigment was absorbed from each area of small bowel studied and, in each instance, conjugated bilirubin- $\mathrm{C}^{14}$ was isolated from the bile. Significant radioactivity was also absorbed after administration of conjugated and unconjugated bilirubin- $\mathrm{C}^{14}$ into isolated loops of duodenum and large bowel. Variations in segmental absorptive surface, blood supply, and intraluminal pressure prevented quantitative comparison of the respective absorption rates, but the results indicated that bilirubin absorption occurred throughout the small and large bowel. Histologic sections of intestinal segments exposed for 8 hours to the highest concentrations of bilirubin and taurocholate employed during these experiments failed to reveal pathologic changes.

$\beta$-Glucuronidase activity of intestinal mucosa. In three assays, rat intestinal mucosa was found to exhibit an average enzymatic activity of $0.21 \mathrm{U}$ (31) per mg wet weight. Considering the entire jejunal and ileal mucosa as one organ, the total enzymatic activity averaged $735 \mathrm{U}$ per animal. In the Gunn rat, $\beta$-glucuronidase activity of intestinal mucosa was similar to that of normal Sprague-Dawley rats.

To determine whether hydrolysis of bilirubin glucuronide was demonstrable in the intestinal lumen, three experiments were performed in which fresh unlabeled bile was instilled into isolated segments of small intestine with intact blood supply. The segmental contents were recovered 2 hours later, diazotized, and chromatographed (14). Eighty to $95 \%$ of the residual bilirubin yielded the conjugated azo derivative, but total recovery from the intestinal segments amounted to less than half of the quantity administered.

\section{DISCUSSION}

During the past several decades, interest in intestinal bile pigment absorption has persisted because of the physiologic and clinical implications of the problem. 1) The occurrence of a significant enterohepatic circulation of bilirubin would increase the hepatic bilirubin load and might contribute to the degree of icterus in hepatic failure.
Similarly, absorbed urobilinoids might compete with bilirubin for hepatic clearance and consequently decrease its rate of biliary excretion. 2) Information on the nature and magnitude of bilirubin absorption would provide insight into the mechanisms involved in the absorption of aglycones (substances capable of forming glucuronides) and glucuronides. An enzymatic apparatus for glucuronide synthesis is believed to function in various portions of the gastrointestinal tract $(35,36)$. It has been suggested that several aglycones either diffuse passively across the intestinal mucosa or are conjugated during an active absorptive process $(16,17)$. Glucuronides so formed cannot diffuse back across the mucosal membrane, nor can glucuronides placed in the intestinal lumen be absorbed without prior hydrolysis. Since bilirubin is an endogenous, potentially toxic $(37,38)$ aglycone, its relationship to these absorptive mechanisms is of particular interest. 3) The magnitude and variability of intestinal absorption of bilirubin and its derivatives have a direct bearing on the quantitation of fecal bile pigment excretion for estimating heme degradation (39-41).

In the studies described, the sum of biliary and urinary excretion of bilirubin and derivatives was considered equivalent to the total intestinal pigment absorption. Implicit was the assumption that after absorption these substances are rapidly excreted. Although this assumption is valid for bilirubin and urobilinoids (42-44), it may not apply to other derivatives of bilirubin (19). Furthermore, it should be noted that radioactive bilirubin was administered in a single pulse rather than by constant infusion, that pigment absorption was studied in postsurgical animals with external biliary drainage, and that absorptive flux rather than net mucosal transfer was measured. Each of these factors should be considered in interpreting the experimental results.

In the experiments performed with normal Sprague-Dawley rats, a considerable proportion of the administered labeled pigment was absorbed. During the early phase, absorption was consistently faster following intraduodenal administration of unconjugated bilirubin than that observed after administration of conjugate, although in the course of 24 hours, the magnitude of total absorption was similar. After instilling either 
pigment into the duodenum, bilirubin- $\mathrm{C}^{14}$ invariably could be crystallized from subsequent bile specimens. When conjugate was given, however, the proportion of total biliary radioactivity recovered in crystalline bilirubin appeared to be smaller than after administration of unconjugated bilirubin. Although the limited number of experiments prevented statistical analysis, the trend is evident from the data in Table II.

These findings are consistent with each of several possible mechanisms of absorption. Bilirubin might be absorbed unaltered as the aglycone, while the conjugated pigment is hydrolyzed prior to its absorption. Alternatively, bilirubin might be conjugated during the absorptive process, as has been postulated for other aglycones (16-18). Finally, conjugated and unconjugated pigment might be absorbed unaltered by independent mechanisms. On the basis of present concepts this last mechanism would appear unlikely, since as a rule, in the absence of active or facilitated transport, water-soluble compounds with molecular weight in excess of 200 are not appreciably absorbed (9). The existence of an apparatus for active absorption of a useless catabolite would seem improbable. Since the product of biliary excretion rather than the absorbed material itself was measured and since absorbed bilirubin undergoes hepatic conjugation prior to reaching the bile, the data obtained in the experiments above did not permit an evaluation of the three possible absorptive mechanisms.

With a different experimental design it was possible to identify the transferred pigment near the site of absorption. In rats, following intraduodenal instillation of unconjugated bilirubin- $\mathrm{C}^{14}$, portal blood was collected at the expected time of peak absorption. In all instances unconjugated bilirubin- $\mathrm{C}^{14}$ could be crystallized from these serum samples, suggesting that the labeled pigment had been absorbed unaltered. However, the amounts of radioactivity recovered, although significant, were small; moreover, the rate of absorption of conjugated bilirubin- $\mathrm{C}^{14}$ was too slow to permit recovery of adequate amounts of radioactivity in portal blood. These difficulties could be overcome by using Gunn rats, which exhibit insignificant hepatic glucuronyl transferase activity and hence fail to excrete bilirubin glucuronide in the bile (27). Consequently, uncon- jugated bilirubin- $\mathrm{C}^{14}$ entering the portal blood after intestinal absorption would be retained in the plasma and could be isolated and crystallized. In contrast, bilirubin conjugated during absorption, or conjugated bilirubin absorbed intact from the intestinal lumen, would appear rapidly in the bile of these rats, since their ability to excrete exogenous conjugated pigment is unimpaired (27). In each study of absorption performed in Gunn rats, irrespective of whether unconjugated or conjugated labeled pigment was administered, unconjugated bilirubin- $\mathrm{C}^{14}$ was identified in the serum, while no significant amount of conjugated bilirubin- $\mathrm{C}^{14}$ could be isolated from bile. These findings are incompatible with the concept that conjugated pigment is absorbed unaltered. On the other hand. they indicate that unconjugated bilirubin is absorbed as such, while conjugated bilirubin must be hydrolyzed before its absorption. These observations would also appear to rule out significant intestinal glucuronide formation in the process of absorption. Since in Gunn rats, however, intestinal glucuronyl transferase activity may be deficient (45), the possibility cannot be excluded that in normal animals, a portion of the absorbed bilirubin may be conjugated during the absorptive process. That this is not a major mechanism of absorption is indicated by the fact that in both Gunn rats and normal animals the magnitude of bilirubin absorption was comparable.

If bilirubin is absorbed from rat intestine while its glucuronide remains unabsorbed, then conjugation may be said to provide a barrier against intestinal reabsorption. Under the conditions of these experiments, the barrier was incomplete; partial conjugate hydrolysis occurred, permitting absorption of bilirubin after intestinal administration of conjugated pigment. Bacteria known to elaborate $\beta$-glucuronidase inhabit the large bowel, and under the operative conditions employed, may have invaded the small bowel (46). Moreover. extracts of intestinal mucosa revealed the presence of mammalian $\beta$-glucuronidase, and recent histochemical studies suggest that $\beta$-glucuronidase activity can be identified in rat mucosal cells near the luminal surface (47). Since after administration of bile into intestinal segments most of the pigment recovered from the bowel was in the form of the glucuronide, it would appear likely that hydrolysis occurs at the mucosal surface 
rather than in the intestinal lumen. Because of incomplete recovery of the infused conjugated pigment, however, the present findings are equally compatible with rapid absorption of an unconjugated bilirubin fraction that may have been formed by hydrolysis within the intestinal lumen

A second defect in the barrier preventing intestinal reabsorption is suggested by the consistent presence of diazo-negative, labeled bilirubin derivatives in bile of animals receiving both unconjugated and conjugated bilirubin- $\mathrm{C}^{14}$. Although in part this material may represent an experimental artifact (19), it appears likely that a fraction of the instilled pigment was converted to bilirubinoid derivatives in the intestinal lumen or during the absorptive process. Since the available techniques for identification and isolation of these compounds are inadequate, the significance of these observations cannot at present be fully evaluated. Although these findings indicate that in the rat the conjugate barrier is incomplete in preventing reabsorption of bilirubin and its derivatives, preliminary observations in man suggest a higher legree of efficiency $(21,48)$.

The present results have a direct bearing on the problem of the enterohepatic circulation of urobilinoids (49). The magnitude of this postulated process has never been adequately defined. Although a minute amount of urobilinogen, presumably derived from the intestinal tract, regularly appears in urine $(39,40,50)$. biliary concentrations of urobilinoids are at the lower limit of measurability (51). Since urobilinogen is more water soluble than bilirubin (52), and since part of the urobilinogen in the colon may still be conjugated with glucuronic acid, a lesser degree of intestinal absorption might be anticipated. Rats prepared with oral neomycin for 10 days before the administration of labeled pigment exhibited negligible concentrations of fecal urobilinogen, but did absorb and excrete $\mathrm{C}^{14}$-labeled pigment in patterns comparable to those in untreated animals. This suggests that in rats the extent of urobilinoid absorption may be relatively small. Because of the recognized species differences in intestinal flora (53), application of this conclusion to human physiology may be premature. Definitive information will be established only after preparation of urobilinoids bearing a suitable label.

\section{SUM MARY}

1. In Sprague-Dawley rats provided with an external biliary fistula, intestinal absorption of unconjugated or conjugated bilirubin- $\mathrm{C}^{14}$ was estimated after infusion of these pigments into the intestinal tract. Radioactivity excreted in bile, urine, and feces was measured, and bilirubin was crystallized from the bile and its specific activity determined.

2. After intestinal administration of either pigment, significant amounts of label appeared in the bile. With unconjugated bilirubin- $\mathrm{C}^{14}$, the initial rate of biliary excretion exceeded that observed after infusion of the conjugate, but in the course of 24 hours cumulative excretion was comparable for both pigment types.

3. Biliary excretion of absorbed label greatly exceeded urinary excretion. In all instances a significant proportion of the biliary radioactivity was present in bilirubin crystallized from bile. The absorptive pattern was not significantly altered by pretreating the rats with oral neomycin.

4. In experiments performed on isolated intestinal loops with intact blood supply, absorption of bilirubin was demonstrated throughout the small and large bowel.

5. Unconjugated or conjugated bilirubin- $\mathrm{C}^{14}$ was administered intraduodenally to Gunn rats. In all instances, unconjugated bilirubin- ${ }^{14}$ was absorbed and retained in plasma, while in contrast, virtually no conjugated bilirubin- $\mathrm{C}^{14}$ appeared in bile. It was concluded that unconjugated bilirubin can be absorbed unaltered, but conjugate must be hydrolyzed before absorption. Supporting evidence for this concept was obtained by crystallyzing unconjugated bilirubin- $\mathrm{C}^{14}$ from the portal venous blood of Sprague-Dawley rats after intraduodenal administration of unconjugated bilirubin- $\mathrm{C}^{\mathbf{1 4}}$.

\section{REFERENCES}

1. Broun, G. O., P. D. McMaster, and P. Rous. Studies on the total bile. IV. The enterohepatic circulation of bile pigment. J. exp. Med. 1923, 37, 699.

2. McMaster, P. D., and R. Elman. Studies on urobilin physiology and pathology. III. Absorption of pigments of biliary derivation from the intestine. J. exp. Med. 1925, 41, 719.

3. Baumgärtel, $\mathrm{T}$. Zur klinischen Diagnostik der biologischen Bilirubinderivate. Arch. inn. Med. $1949,1,40$. 
4. Watson, C. J. The pyrrol pigments, with particular reference to normal and pathological hemoglobin metabolism in Handbook of Hematology. $\mathrm{H}$. Downey, Ed. New York, Paul B. Hoeber, 1938, p. 2480 .

5. With, T. K. Biologie der Gallenfarbstoffe. Stuttgart, Georg Thieme, 1960 p. 68.

6. Crane, R. K. Intestinal absorption of sugars. Physiol. Rev. 1960, 40, 789.

7. Hogben, C. A. M. The first common pathway. Fed. Proc. 1960, 19, 864.

8. Laster, L., and F. J. Ingelfinger. Intestinal absorption-aspects of structure, function and disease of the small-intestine mucosa. New Engl. J. Med. 1961, 264, 1138, 1192, 1246.

9. Wilson, T. H. Intestinal Absorption. Philadelphia, W. B. Saunders, 1962, pp. 40-68.

10. Schanker, L. S., P. A. Shore, B. B. Brodie, and C. A. M. Hogben. Absorption of drugs from the stomach. I. The rat. J. Pharmacol. exp. Ther. 1957, 120, 528.

11. Hogben, C. A. M., D. J. Tocco, B. B. Brodie, and L. S. Schanker. On the mechanism of intestinal absorption of drugs. J. Pharmacol. exp. Ther. 1959, 125, 275.

12. Schanker, L. S. Absorption of drugs from the rat colon. J. Pharmacol. exp. Ther. 1959, 126, 283.

13. Billing, B. H., and G. H. Lathe. The excretion of bilirubin as an ester glucuronide, giving the direct van den Bergh reaction. Biochem. J. 1956, 63, $6 \mathrm{P}$.

14. Schmid, R. Direct-reacting bilirubin, bilirubin glucuronide, in serum, bile, and urine. Science 1956, 124, 76.

15. Scholderer, H. Untersuchungen über die Resorption von Bilirubin aus dem Darm. Biochem. Z. 1933, 257, 145.

16. Tapley, D. F., R. Herz, Jr., J. E. Ross, T. F.Deuel, and L. Leventer. Glucuronide formation in the active transport of amino acid and thyroxine analogues by rat intestine. Biochim. biophys. Acta (Amst.) 1960, 43, 344.

17. Herz, R., Jr., D. F. Tapley, and J. E. Ross. Glucuronide formation in the transport of thyroxine analogues by rat intestine. Biochim. biophys. Acta (Amst.) 1961, 53, 273.

18. Schachter, D., D. J. Kass, and T. J. Lannon. The biosynthesis of salicyl glucuronides by tissue slices of various organs. J. biol. Chem. 1959, 234, 201.

19. Ostrow, J. D., L. Hammaker, and R. Schmid. The preparation of crystalline bilirubin- $\mathrm{C}^{\mathbf{1 4}}$. J. clin. Invest. 1961, 40, 1442.

20. Lester, R., J. D. Ostrow, and R. Schmid. Enterohepatic circulation of bilirubin. Nature (Lond.) 1961, 192, 372.

21. Lester, R., and R. Schmid. The mechanism of intestinal absorption of bilirubin (abstract). J. clin. Invest. 1962, 41, 1379.
22. Gilbertsen, A. S., I. Bossenmaier, and R. Cardinal. Enterohepatic circulation of unconjugated bilirubin in man. Nature (Lond.) 1962, 196, 141.

23. Schmid, R., and L. Hammaker. Metabolism and disposition of $\mathrm{C}^{41}$-bilirubin in congenital non-hemolytic jaundice. Trans. Ass. Amer. Phycns 1962, $75,220$.

24. Dawson, A. M., and K. J. Isselbacher. Studies on lipid metabolism in the small intestine with observations on the role of bile salts. J. clin. Invest. 1960, 39, 730 .

25. Ostrow, J. D., J. H. Jandl, and R. Schmid. The formation of bilirubin from hemoglobin in vic'o. J. clin. Invest. 1962, 41, 1628.

26. Axelrod, J., R. Schmid, and L. Hammaker. A biochemical lesion in congenital, non-obstructive, non-hæmolytic jaundice. Nature (Lond.) 1957, $180,1426$.

27. Schmid, R., J. Axelrod, L. Hammaker, and R. I. Swarm. Congenital jaundice in rats, due to a defect in glucuronide formation. J. clin. Invest. 1958, $37,1123$.

28. Malloy, H. T., and K. A. Evelyn. The determination of bilirubin with the photoelectric colorimeter. J. biol. Chem. 1937, 119, 481.

29. Najjar, V. A., and B. Childs. The crystallization and properties of serum bilirubin. J. biol. Chem. 1953, 204, 359.

30. Kamen, Martin D. Isotopic Tracers in Biology. An Introduction to Tracer Methodology, 3rd ed. New York, Academic Press, 1957, pp. 96-100.

31. Talalay, P., W. H. Fishman, and C. Huggins. Chromogenic substrates. II. Phenolphthalein glucuronic acid as substrate for the assay of glucuronidase activity. J. biol. Chem. 1946, 166, 757.

32. Wilson, T. H., and G. Wiseman. The use of sacs of everted small intestine for the study of the transference of substances from the mucosal to the serosal surface. J. Physiol. (Lond.) 1954, 123. 116.

33. Middleton, J. E., and W. J. Griffiths. Rapid colorimetric micro-method for estimating glucose in blood and C.S.F. using glucose oxidase. Brit. med. J. 1957, 2, 1525.

34. Rosenberg, T. On accumulation and active transport in biological systems. I. Thermodynamic considerations. Acta chem. scand. 1948, 2, 14.

35. Hartiala, K. J. Studies on detoxication mechanisms. III. Glucuronide synthesis of various organs with special reference to the detoxifying capacity of the mucous membrane of the alimentary canal. Ann. med. exp. Fenn. 1955, 33, 239.

36. Shirai, Y., and T. Ohkubo. Synthesis of glucuronides by tissue slices. I. J. Biochem. (Tokyo) 1954, 41, 341.

37. Editorial. Toxicity of bilirubin. New Engl. J. Med. 1962, 267, 308.

38. Ernster, L., L. Herlin, and R. Zetterström. Experimental studies on the pathogenesis of kernicterus. Pediatrics 1957, 20, 647. 
39. Schwartz, S., V. Sborov, and C. J. Watson. Studies of urobilinogen. IV. The quantitative determination of urobilinogen by means of the Evelyn photoelectric colorimeter. Amer. J. clin. Path. 1944, 14, 598.

40. Watson, C. J., and V. Hawkinson. Studies of urobilinogen. VI. Further experience with the simple quantitative Ehrlich reaction. Corrected calibration of the Evelyn colorimeter with a pontacyl dye mixture in terms of urobilinogen. Amer. J. clin. Path. 1947, 17, 108.

41. Cartwright, G. E. Diagnostic Laboratory Hematology, 2nd ed. New York, Grune \& Stratton, 1958, pp. 233-235.

42. With, T. K. The urobilinogen tolerance test as functional liver test. Acta med. scand. 1946, 125, 588.

43. Watson, C. J. in Urobilinogen in human bile, I. R. Jankelson. Gastroenterology, 1944, 3, 292.

44. Lester, R. Urobilin excretion in the rat. In preparation.

45. Arias, I. M., L. Johnson, and S. Wolfson. Studies of extrahepatic glucuronide formation in normal and Gunn's rats (abstract). Clin. Res. 1960, 8, 28.

46. Martini, G. A., E. A. Phear, B. Ruebner, and S. Sherlock. The bacterial content of the small intestine in normal and cirrhotic subjects: relation to methionine toxicity. Clin. Sci. 1957, 16, 35.

47. Watanabe, K., and Fishman, W. H. Personal communication.

48. Lester, R., and R. Schmid. Intestinal absorption of bilirubin in humans. New Engl. J. Med. In press.

49. Watson, C. J. The pyrrol pigments and hemoglobin metabolism. Minn. Med. 1956, 39, 403.

50. Cartwright, G. E. Diagnostic Laboratory Hematology, 2nd ed. New York, Grune \& Stratton, 1958, pp. 220-225.

51. With, T. K. Bilirubin and urobilinoid contents of human bile. Acta med. scand. 1945, 122, 513.

52. With, T. K. Biologie der Gallenfarbstoffe. Stuttgart, Georg Thieme, 1960, p. 17.

53. Norman, A., and J. Sjövall. On the transformation and enterohepatic circulation of cholic acid in the rat. J. biol. Chem. 1958, 233, 872. 